\title{
COMMENT
}

\section{Role of diatoms in copepod production: good, harmless or toxic?}

\author{
Sigrún H. Jónasdóttir ${ }^{1, *}$, Thomas Kiørboe ${ }^{1}$, Kam W. Tang ${ }^{2}$, Michael St. John ${ }^{1}$, André W. Visser ${ }^{1}$, \\ Enric Saiz ${ }^{3}$, Hans G. Dam ${ }^{2}$ \\ ${ }^{1}$ Danish Institute for Fisheries Research, Department of Marine and Coastal Ecology, Kavalergărden 6, DK-2920 Charlottenlund, Denmark \\ ${ }^{2}$ Department of Marine Sciences, University of Connecticut, Groton, Connecticut 06340-6097, USA \\ ${ }^{3}$ Institut de Ciències del Mar, CSIC, P. Nacional s/n, E-08039 Barcelona, Spain
}

Numerous recent studies have challenged the classical view that copepod production in the ocean is primarily based on pelagic diatoms. Kleppel (1993), in particular, has argued that copepods in nature feed mainly on other microplankters (dinoflagellates, ciliates) which primarily account for reproduction, and that diatoms alone provide an insufficient diet for reproduction. More recently, several authors have argued that diatoms can be toxic or deleterious to copepods by preventing their eggs from hatching or causing the eggs to hatch into malformed, non-viable nauplii (Ban et al. 1997 and references therein). While there is now general consensus in the literature that some species of diatoms are nutritionally insufficient for copepod reproduction (Støttrup \& Jensen 1990 Kleppel 1993, Jónasdóttir \& Kiørboe 1996), the idea that they are toxic remains controversial. Whether diatoms are toxic or nutritionally incomplete makes a major difference to the impact on pelagic food web dynamics and to our understanding of the basis for fish production in the oceans. Planktonic copepods account for about $80 \%$ of the mesozooplankton biomass in the ocean and thus provide the most important link between lower and higher trophic levels in the pelagic food web. Therefore, if toxic, the presence of diatom blooms would reduce copepod population sizes, mesozooplankton secondary production and, hence, food for planktivorous fishes. In this comment we examine the evidence for the toxicity hypothesis, argue that it has not been rigorously tested in an ecologically meaningful way, and propose a possible avenue to follow.

Evidence. Several studies have clearly demonstrated that some diatom diets result in lower egg production and/or hatching success and/or a higher frequency of

•E-mail: sjo@dfu.min.dk malformed nauplii than do, for example, dinoflagellate and flagellate diets (Støttrup \& Jensen 1990, Jónasdóttir \& Kiørboe 1996, Ban et al. 1997). However, these observations do not allow us to decide whether the inadequacies of these diatom diets are due to toxicity or nutritional insufficiency. Copepod eggs are typically rich in lipids (Gatten et al. 1980) and essential fatty acids are therefore potentially limiting nutritional components of diatom diets, as demonstrated by both laboratory studies (Jónasdóttir \& Kiørboe 1996) and field observations (Pond et al. 1996). Deformities, reduced egg production and hatchability are all wellestablished symptoms of essential fatty acid deficient diets in other marine organisms, including crustaceans (reviewed e.g. in Watanabe 1982, Harrison 1990). There are several other possibly limiting constituents (see Harrison 1990). Potential toxic compounds, on the other hand, have not yet been identified, with the exception of a few diatom species that have toxins similar to those isolated from many dinoflagellates (Bates et al. 1993).

Probably the strongest evidence from feeding studies that diatoms can have deleterious effects on egg production and hatchability was provided by Chaudron et al. (1996). These authors found, in accordance with other studies, that negative effects on egg hatching in Calanus helgolandicus only occurred after several days of feeding on the examined diatoms. They also found that egg hatching success and the length of the time-lag both decreased with increasing concentration of diatoms and, hence, feeding and egg production. They considered this evidence that an inhibitory compound was accumulating in the gonads of the copepod. However, an alternative explanation is equally well supported by their observations, i.e. that the copepod exhausts its own storage of a limiting 
nutritional component essential for hatching and that depletion is faster when egg production is high.

Using phytoplankton extracts, where the eggs are exposed to phytoplankton compounds at increasing extract concentrations, has been applied to test for possible toxicity of diatoms. These experiments suggest a toxic or deleterious effects of diatom extracts on embryonic development and hatching (Poulet et al. 1994, Ianora et al. 1995, Uye 1996). However, this effect is evident only at concentrations that exceed those encountered in nature by many orders of magnitude. In the experiments of Jónasdóttir \& Kiørboe (1996), the negative effects of diatom extracts on hatching disappeared when oxygen was bubbled through the extract solutions, suggesting that the effect was due to the anoxia that developed in this rich organic soup. More important, however, is that such extract experiments are ecologically irrelevant. This is because the extracted solutes may be very different from the solutes that leak out of or are exuded by a diatom (Dam \& Tang 1998). Components of the food that are potentially toxic to egg hatching are, by necessity, mediated by the female and, thus, need to be examined by feeding experiments. Likewise, potential toxic effects of diatom exudates need to be examined by applying exudates, not extracts. Similar criticism may apply to the experiments of Shaw et al. (1997) in which they found that high concentrations of extracts of some diatoms acted to deter feeding of copepods. Hay (1996, p. 107) characterized this type of extract experiments: 'Attempts to assess the physiological effects of prey metabolites on consumers by dissolving metabolites into water holding the consumer have minimal ecological relevance and should be discontinued. Such procedures may be no more realistic than suffocating humans in chocolate syrup and then concluding that chocolate is toxic.'

Several field observations may throw light on the significance of diatoms as a potential basis of copepod nutrition, reproduction and growth. Firstly, it is a general observation in temperate waters that copepods respond positively to seasonal diatom blooms, both in terms of egg production (e.g. Dam et al. 1994, Kiørboe \& Nielsen 1994) and population increases (e.g. Krause \& Thrams 1983). Secondly, dietary lipid tracer studies have repeatedly demonstrated that a diatom-based food chain leads to higher growth rate and better condition of fish larvae - which feed on copepods - compared to a dinoflagellate-based food chain (St. John \& Lund 1996, Hansen 1998). Finally, the only field study that has simultaneously monitored egg hatching success of copepods and phytoplankton species composition (Pond et al. 1996) found no negative relation between hatching success of Calanus helgolandicus eggs and abundance of diatoms. All the field evidence is, therefore, consistent with nutritional insufficiency of diatoms if one assumes that the diatoms provide the stable food and that alternative food sources (ciliates, dinoflagellates) complement the diet to make it nutritionally complete. The field evidence may also, however, be consistent with the idea that diatoms are toxic (at least if eaten), but only if one assumes that the copepods feed mainly or solely on the non-diatom components of the microplankton.

How can we distinguish between a nutritionally insufficient and a toxic phytoplankter? Because of the conceptual and practical problems with extract experiments, the experimental examination of whether a particular phytoplankton species is toxic or nutritionally insufficient has to come from feeding experiments. Experiments in which a good (X) and a suspected poor (Y) (nutritionally insufficient or toxic) phytoplankter are mixed (as in Schmidt \& Jónasdóttir 1997) have the potential to provide the evidence. Generally, in the simplest case, if $\mathrm{Y}$ is nutritionally insufficient, mixing with $X$ would remove the 'deleterious' effects. On the other hand, if $Y$ is toxic, mixing with $X$ would not remove the effect. Consider an experiment in which species $\mathrm{X}$ and $\mathrm{Y}$ are given in varying proportions for a constant total biomass concentration, less the saturating concentration for egg production. The possible responses are schematically presented in Fig. 1. A reference line is defined as the straight line connecting observations (egg production or hatching) at $100 \% \mathrm{Y}$ (point $\mathrm{A}$ ) and $100 \% \mathrm{X}$ (point $\mathrm{B}$ ) and can be anywhere between line 1 and line 2 in Fig. 1. Depending on food quality or toxicity, observations for the mixed diets will fall on, above or. below the reference line.

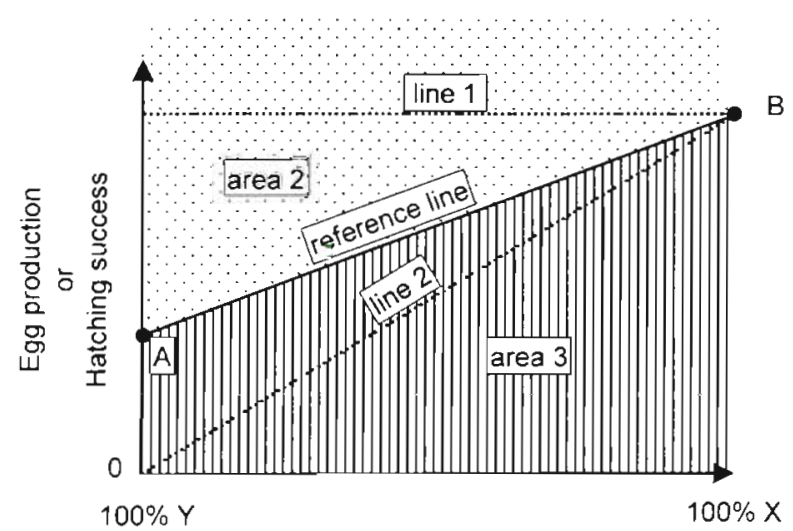

Fig. 1. Possible outcomes in terms of egg production and egg hatching success of experiments in which a good (X) and a suspected poor ( $\mathrm{Y}$ ) (nutritionally insufficient or toxic) phytoplankton species are offered in different proportions in mixed suspensions to a copepod. Total biomass concentration is constant and non-saturating for egg production. Data on line 1. $Y$ as good as $X_{\text {; }}$ data in area 2: Y non-toxic but of lower nutritional value than $X_{;}$data in area $3: Y$ is toxic, or $Y$ is non-toxic and of low nutritional value and the copepod exerts prey switching. Reference line and line 2 explained in text 
(1) $Y$ is as good as $X$ for production of viable eggs: Both egg production and hatching will fall on the reference line. If the clearance rates on the 2 species are the same, then the results would be independent of the proportion of $X$ and $Y$ in the mixture and the reference line will be horizontal, i.e. line 1 in Fig. 1. However, if the clearance rates on $X$ and $Y$ are different, for example owing to different sizes, then egg production rate would increase with increasing proportion of the alga which yields the highest clearance rates. Point $A$ would be lower than point $B$ (or vice versa) but the observations would still fall on the reference line, for example the one sketched in Fig. 1.

(2) $Y$ is non-toxic, but of lower nutritional value than $X$ : Both egg production and hatching success would fall on their respective reference lines. If $\mathrm{Y}$ has no nutritional value then the reference line would lie on line 2 in Fig. 1.

(3) $Y$ is toxic: In this case point A would likely be zero egg production and/or hatching success (i.e. reference line would equal line 2 in Fig. 1). Both egg production and egg hatching success would fall below their respective reference lines, and observations for the mixtures would cluster in area 3.

(4) Y has a nutritional supplement: Egg production and/or hatching success would curve upward above their respective reference lines and fall in area 2 in Fig. 1.

Thus, toxicity would imply a 'type 3' response (Fig. 1). However, a type 3 response does not necessarily imply toxicity. Prey switching could yield a similar response if diet $Y$ is inferior to diet $X$. Prey switching, which implies that the predator feeds preferentially on the most abundant prey, has been demonstrated in several copepod species in laboratory experiments (e.g. Landry 1981). To distinguish between toxicity and prey switching requires measurements of actual ingestion rates (at least of species $\mathrm{X}$ ). Fig. 2 demonstrates how the 3 different responses (i.e. $\mathrm{Y}$ is good, harmless or toxic) would become manifest if egg production or egg hatching is plotted as a function of ingestion rate of species $X$. The response in egg production rate and hatching success depicted in Fig. 2 also applies to situations in which the combined concentration of $\mathrm{X}$ and $\mathrm{Y}$ becomes saturating for egg production.

There is 1 hypothetical exception to the patterns in Figs. 1 \& 2. Assume that species $X$ and $Y$ provide an exactly balanced diet for production of eggs but that $Y$ is deficient in some substance required for the produced eggs to hatch. Then, potentially, eggs produced on a mixed diet would all have too little 'hatching substance' and none would hatch. That would appear as a type 3 response. Therefore, to confirm that a type 3 response actually implies toxicity of species $Y$ requires that the experiments be repeated with species $X$ replaced by another nutritionally complete and non-toxic species.

In conclusion, then, neither field observations nor laboratory experiments have so far provided conclusive and ecologically meaningful tests of the hypothesis that diatoms in general are toxic to copepods and prevent their embryos from developing normally. However, the frequent observation that copepods do in fact feed on diatoms at high rates, both in laboratory experiments and in the field, as well as the apparent lack of a prey selection mechanism against diatoms (as has been demonstrated for toxic dinoflagellates, e.g. Huntley et al. 1986), makes the toxicity hypothesis difficult to understand in an evolutionary context. If this hypothesis were true, an entirely new interpretation of copepod feeding behavior would be required. We hope this comment will prompt conclusive experiments to be conducted.
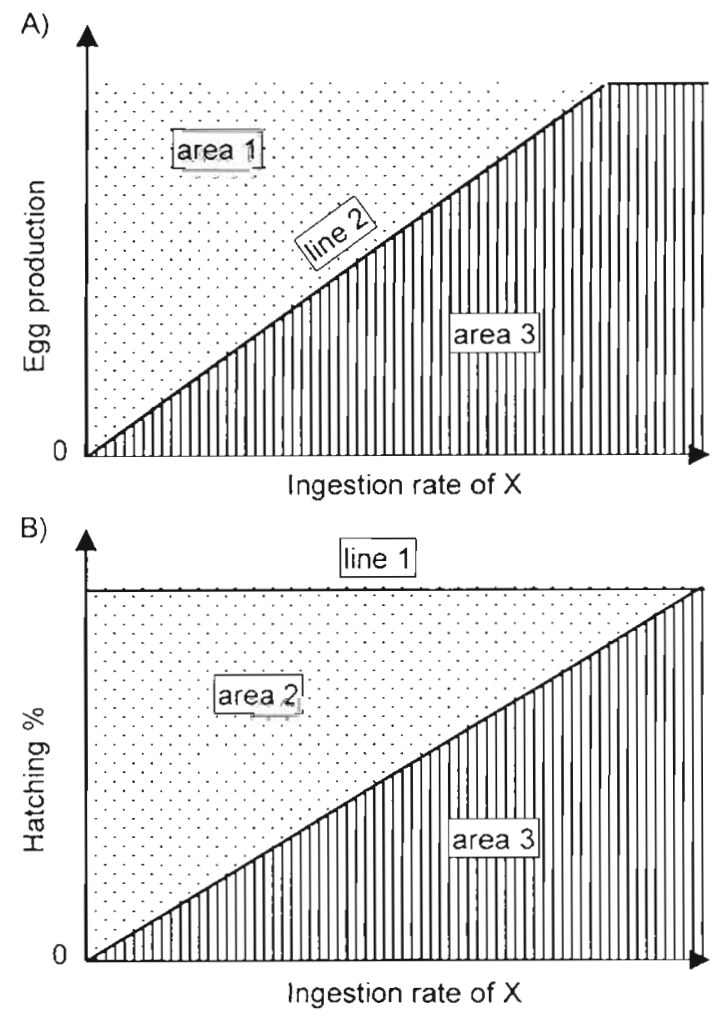

Fig. 2. Possible outcomes in terms of (A) egg production and $(B)$ egg hatching success of experiments in which a good (X) and a suspected poor ( $\mathrm{Y}$ ) (nutritionally insufficient or toxic) phytoplankton species are offered in mixed suspensions to a copepod. Plotted as function of ingestion rate of species $X$. Line 2 in (A) is the functional response in egg production rate to ingestion rate of $X$. Data in area $1(A)$ or on line $1(B)$ : $Y$ is non-toxic and of some nutritional value; data on line $2(A)$ or in area $2(B)$ : $Y$ is non-toxic, but of no nutritional value; data in area $3(A$ and $B)$ : $Y$ is toxic 


\section{LITERATURE CITED}

Ban S, Burns C, Castel J, Chaudron Y, Christou E, Escribano R, Umani SF, Gasparini S, Rulz FG, Hoffmeyer M, Ianora A, Kang HK, Laabir $M$, Lacoste A, Miralto A. Ning X, Poulet S, Rodriguez V. Runge J, Shi J, Starr M, Uye SI, Wang $Y$ (1997) The paradox of diatom-copepod interactions. Mar Ecol Prog Ser 157:287-293

Bates SS, Worms J, Smith JC (1993) Effects of ammonium and nitrate on growth and domoic acid production by Nitzschia pungens in batch culture. Can J Fish Aquat Sci 50:1248-1254

Chaudron Y, Poulet SA, Laabir M, Ianora A, Miralto A (1996) Is hatching success of copepod eggs diatom densitydependent? Mar Ecol Prog Ser 144:185-193

Dam HG, Peterson WT, Bellantoni DC $(1994)$ Seasonal feeding and fecundity of the calanoid copepod Acartia tonsa in Long Island Sound: is omnivory important to egg production? Hydrobiologia 292/293:191-199

Dam HG, Tang KW (1998) Do phytoplankton exudates affect the hatching success of copepod eggs? EOS 79:101

Gatten RR, Sargent JR, Forsberg TEV, O'Hara SCM, Corner EDS (1980) On the nutrition and metabolism of zooplankton. XIV. Utilization of lipid by Calanus helgolandicus during maturation and reproduction. J Mar Biol Assoc UK 60:391-399

Hansen BW (1998) Trophic interactions and tracer lipid content in plankton along 64 to $72^{\circ} \mathrm{N}$ off West Greenland. EOS 79:102

Harrison KE (1990) The role of nutrition in maturation, reproduction and embryonic development of decapod crustaceans: a review. J Shellfish Res 9:1-28

Hay ME (1996) Marine chemical ecology: what's known and what's next? J Exp Mar Biol Ecol 200:103-134

Huntley M, Sykes P, Rohan S, Marin V (1986) Chemicallymediated rejection of dinoflagellate prey by the copepods Calanus pacificus and Paracalanus parvus: mechanism, occurrence and significance. Mar Ecol Prog Ser 28: $105-120$

Ianora A, Poulet SA, Miralto A (1995) A comparative study of the inhibitory effect of diatoms on the reproductive biology of the copepod Temora stylifera. Mar Biol 121:533-539

Jónasdóttir SH, Kiorboe T (1996) Copepod recruitment and food composition: do diatoms affect hatching success? Mar Biol 125:743-750

Kiorboe T, Nielsen TG (1994) Regulation of zooplankton biomass and production in a temperate, coastal ecosystem 1. Copepods. Limnol Oceanogr 39:493-507

Kleppel GS (1993) On the diets of calanoid copepods. Mar Ecol Prog Ser 99:182-195

Krause M. Thrams J (1983) Zooplankton dynamics during FLEX'76. In: Sundeman J, Lenz W (eds) North Sea dynamics. Springer Verlag, Berlin, p 632-661

Landry MR (1981) Switching between herbivory and carnivory by the planktonic marine copepod Calanus pacificus. Mar Biol 65:77-82

Pond D, Harris R, Head R, Harbour D (1996) Environmental and nutritional factors determining seasonal variability in the fecundity and egg viability of Caldnus helgolandicus in coastal waters off Plymouth, UK. Mar Ecol Prog Ser 143: $45-63$

Poulet SA, Ianora A, Miralto A, Meijer L (1994) Do diatoms arrest embryonic development in copepods? Mar Ecol Prog Ser 111:79-86

Schmidt K, Jónasdóttir SH (1997) Nutritional quality of two cyanobacteria: how rich is 'poor' food? Mar Ecol Prog Ser $151: 1-10$

Shaw BA, Andersen RJ, Harrison PJ (1997) Feeding deterrent and toxicity effects of apo-fucoxanthinoids and phycotoxins on a marine copepod (Tigriopus californicus). Mar Biol 128:273-280

St. John MA, Lund T (1996) Lipid biomarkers: linking the utilization of frontal plankton biomass to enhanced condition of Juvenile North Sea cod. Mar Ecol Prog Ser 131:75-85

Støttrup JG, Jensen J (1990) Influence of algal diet on feeding and egg-production of the calanoid copepod Acartia tonsa Dana. J Exp Mar Biol Ecol 141:87-105

Uye SI (1996) Induction of reproductive failure in the planktonic copepod Calanus pacificus by diatoms. Mar Ecol Prog Ser 133:89-97

Watanabe $T$ (1982) Lipid nutrition in tish. Comp Biochem Physiol 73B:3-15 